Л.Ю. ТРУХАН, к.М.Н., Д.И. ТРУХАН, Д.М.Н., профессор

Омский государственный медицинский университет Минздрава России

\title{
СТОМАТОЛОГИЧЕСКИЕ ПРОБЛЕМЫ ГАСТРОЭНТЕРОЛОГИЧЕСКИХ ПАЦИЕНТОВ
}

\author{
И ВОЗМОЖНЫЕ ПУТИ ИХ РЕШЕНИЯ
}

\begin{abstract}
В статье рассмотрены возможные изменения со стороны органов и тканей полости рта при заболеваниях органов пищеварения, а также изменения, возникающие под влиянием лекарственной терапии этих заболеваний. Для профилактики и лечения воспалительных изменений полости рта у гастроэнтерологических пациентов рекомендовано применение натуральных растительных препаратов (зубные пасты, ополаскиватели, спреи).
\end{abstract}

Ключевые слова: стоматология, полость рта, болезни органов пищеварения, лекарственная терапия.

\section{L.Yu. TRUKHAN, PhD, D.I. TRUKHAN, MD, PhD, professor STOMATOLIGICAL PROBLEMS OF GASTROENTEROLOGICAL PATIENTS AND THEIR POSSIBLE SOLUTIONS Omsk state medical university Ministry for Public Health of the Russian Federation}

The article discusses possible changes in the organs and tissues of the oral cavity in diseases of the digestive system, as well as changes occurring under the influence of drug therapy of these diseases. For the prevention and treatment of inflammatory changes of the oral cavity in gastroenterological patients may use drug and Parodontocide.

Keywords: stomatology, the oral cavity, digestive system diseases, drug therapy.

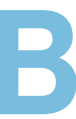

системе взаимоотношений врача-интерниста с другими специалистами наименее изученными являются аспекты их взаимодействия с врачомстоматологом. В первую очередь это связано с изолированным структурным расположением городских и областных стоматологических клиник от других лечебных учреждений. Во вторую очередь следует отметить взаимную недооценку изменений со стороны органов и тканей полости рта при различных заболеваниях внутренних органов и под влиянием лекарственной терапии этих заболеваний [1, 2].

Вместе с тем часто причина обращения пациента к стоматологу обусловлена наличием соматической патологии, и на прием к врачу-стоматологу приходят не абсолютно соматически здоровые пациенты, проблемы которых ограничиваются полостью рта. С другой стороны, наличие определенных изменений со стороны органов и тканей полости рта и соответствующая консультативная помощь стоматолога могут помочь интернисту в диагностике и адекватном лечении пациента $[1,2]$.

Болезни органов пищеварения часто сопровождаются различными изменениями со стороны органов и тканей полости рта. Это объясняется морфофункциональным сходством слизистой оболочки полости рта и пищеварительного тракта, а также наличием тесной взаимосвязи различных отделов желудочно-кишечного тракта с его начальным отделом - полостью рта, осуществляемой посредством анатомических, физиологических и гуморальных взаимосвязей [1, 3, 4].

При ряде заболеваний, например гастроэзофагеальной рефлюксной болезни (ГЭРБ), воспалительных заболе- ваниях кишечника (болезнь Крона, неспецифический язвенный колит), наличие у пациента изменений со стороны органов и тканей полости рта вносит определенный вклад в их диагностику [5-7].

Специфические стоматологические симптомы ГЭРБ (жжение языка, щек, нарушение вкусовых ощущений, поражение твердых тканей зубов - истончение и эрозии эмали зубов, кариес, пародонтит, гранулема) выделены отдельной группой среди внепищеводных клинических проявлений заболевания [8, 9]. Следует отметить, что термин «пародонтит» является синонимом термина «periodontitis» в английской транскрипции. Группа экспертов по ГЭРБ (Монреаль, 2006) отмечает, что рефлюкскариес является достоверно связанным с ГЭРБ внепищеводным симптомом заболевания. Специфичным клиническим симптомом для ГЭРБ является и слюнотечение вследствие ваготонии, характерной для большинства пациентов с заболеваниями верхних отделов пищеварительного тракта $[9,10]$.

При заболеваниях желудка к субъективным жалобам пациента относятся ощущение жжения, болезненности в различных отделах языка, особенно при приеме раздражающей пищи. Парестезии и неприятные ощущения в языке являются специфичными симптомами дефицита витаминов группы В, особенно витамина $B_{12}$. Пациенты часто указывают на извращение вкусовых ощущений, в первую очередь на металлический привкус во рту, особенно по утрам [9].

Практически у всех больных язвенной болезнью желудка и 12-перстной кишки выявляется гингивит, тяжесть которого находится в прямой зависимости от 
характера течения и давности основного заболевания. В период обострения язвенной болезни наблюдаются отек слизистой оболочки полости рта, гиперемия и гипертрофия нитевидных и грибовидных сосочков языка, снижается вкусовая чувствительность к сладкому $[1,4]$.

Большое значение в развитии заболеваний желудка и 12-перстной кишки придается инфекционному фактору инфекции Helicobacter pylori (Нp). Естественным резервуаром для Нр могут служить пародонтальные карманы. Обнаружение Н. pylori в зубном налете (зубной бляшке) $[11,12]$, а в последующем в ротовой жидкости и содержимом пародонтальных карманов [13-15], позволяет рассматривать полость рта как резервуар и дополнительный источник реинфицирования организма Н. pylori после проведенной эрадикации. В ряде исследований отмечены положительные ассоциации между наличием $\mathrm{H}$. pylori в зубном налете и желудке [16, 17] и с желудочно-пищеводным рефлюксом $[18,19]$. Таким образом, присутствие Нр в полости рта может быть источником реинфекции у пациентов с язвенной болезнью и хеликобактер-ассоциированным гастритом.

При панкреатите и хронических заболеваниях печени возможно наличие в клинической картине синдрома Шегрена (Съегрена), или «сухого синдрома», при котором характерно аутоиммунное поражение слюнных желез. Для распознавания синдрома Шегрена используют триаду признаков: сухой кератоконъюнктивит; ксеростомия и/ или паренхиматозный паротит; наличие заболевания в патогенезе которого участвуют аутоиммунные реакции. Наличие первых двух признаков позволяет поставить диагноз «сухого» синдрома, болезни Шегрена, наличие всех трех признаков - синдрома Шегрена (вторичного синдрома Шегрена). Болезнь Шегрена (первичный синдром Шегрена) - хроническое воспалительное заболевание экзокринных желез, прежде всего слюнных и слезных, с постепенным развитием их секреторной недостаточности в сочетании с различными системными проявлениями [20, 21].

Для клинической картины болезни Шегрена характерны следующие изменения со стороны органов и тканей полости рта: рецидивирующий паротит или постепенное увеличение слюнных желез; сухость слизистых полости рта (носоглотки) и быстрое развитие множественного, преимущественно пристеночного, кариеса зубов. Одним из ведущих симптомов является ксеростомия, проявляющаяся в первую очередь при жевании и глотании. Из-за отсутствия слюны с ее бактерицидным действием часто развиваются трещины губ, гингивит, язвенный стоматит, кариес зубов. К возможным осложнениям относятся инфицирование и развитие лимфосаркомы слюнных желез [1, 20, 21].

У пациентов с патологией поджелудочной железы часто выявляются различные иммунные нарушения [22, 23]. Тесную связь поджелудочной железы и слюнных желез демонстрирует наличие антител к тканевому антигену слюнных желез у 1/3 больных хроническим панкреатитом с наличием антител к тканевому антигену поджелудочной железы.
Воспалительные изменения слизистой оболочки полости рта могут служить первыми клиническими проявлениями болезни Крона или же наблюдаться одновременно с поражением подвздошной и толстой кишок [24, 25]. Чаще всего обнаруживаются афтозный стоматит, макрохейлия (увеличение губ) или изменения рельефа слизистой оболочки в виде «булыжной мостовой». Приблизительно у $10 \%$ больных с неспецифическим язвенным колитом обнаруживаются афты на слизистой оболочке ротовой полости, исчезающие по мере снижения активности основного заболевания. Практически специфичной для язвенного колита считается пиостома с вегетациями (Pyostomatis vegetans). При этом на слизистой оболочке щек, губ, неба возникают припухлости, переходящие в темные щелевидные язвы и папиллярные разрастания.

Появление у пациента жалоб и изменений со стороны органов и тканей полости рта возможно и вследствие проводимой лекарственной терапии заболеваний пищеварительной системы [1, 2, 26, 27].

Так, прием пациентами антисекреторных препаратов (ингибиторы протонного насоса, блокаторы гистаминовых $\mathrm{H}_{2}$-рецепторов, антациды и алгинаты) может сопровождаться появлением сухости во рту, изменением вкусовых ощущений. Регулятор моторной функции ЖКТ итоприда гидрохлорид может вызывать повышенное слюноотделение [10]. Среди побочных эффектов омепразола, эзомепразола, рабепразола указывается стоматит, у декслансопразола - сухость во рту, кандидоз полости рта, отек слизистой полости рта.

При ряде заболеваний, например гастроэзофагеальной рефлюксной болезни, воспалительных заболеваниях кишечника (болезнь Крона, неспецифический язвенный колит), наличие у пациента изменений со стороны органов и тканей полости рта вносит определенный вклад в их диагностику

При приеме антибиотиков возможно развитие кандидоза слизистой оболочки полости рта, обусловленное биологическим действием препаратов. Использование в схеме эрадикации хеликобактерной инфекции 1-й линии кларитромицина предполагает возможность развития нарушения вкуса (искажение и изменение восприятия вкуса); глоссита, стоматита, изменения цвета языка и цвета зубов (в большинстве случаев обратимое). Обесцвечивание зубов обычно восстанавливается профессиональной чисткой у стоматолога $[1,2,4]$.

Назначение пациенту схемы эрадикации Нp 2-й линии предполагает появление возможных побочных эффектов метронидазола и тетрациклина со стороны органов и тканей полости рта. Так, прием метронидазола может сопровождаться изменением вкусовых ощущений, металлическим привкусом во рту, сухостью во рту, возможно развитие глоссита и стоматита. Применение тетрациклина, кроме общеизвестного необратимого изменения цвета зубов у детей в период их развития, предполагает возможность появления сухости во рту, глоссита, 
изменения цвета языка. При использовании антибиотиков резерва - рифабутина и рифампицина возможно красно-коричневое окрашивание языка, слюны и других биологических жидкостей организма.

Прием целого ряда препаратов для лечения заболеваний желчного пузыря и желчевыводящих путей также может сопровождаться побочными эффектами со стороны органов и тканей полости рта - сухостью во рту (метацин, платифиллин, атропин, пирензепин, гиосцина бутилбромид, бенциклана фумарат), изменением вкусовых ощущений. Развитие аллергических реакций возможно при приеме пинаверия бромида, бенциклана фумарата, мебеверина (крапивница, отек Квинке), гиосцина бутилбромида (кожная сыпь).

Развитие аллергических реакций, в том числе с клиническими проявлениями со стороны слизистой оболочки полости рта, может отмечаться при использовании ингибиторов протеаз (ингитрил, контрикал, гордокс) и приеме ферментных препаратов (препаратов панкреатина) у пациентов с патологией поджелудочной железы.

Лечение хронических заболеваний печени противовирусными препаратами (интерфероны, аналоги нуклеозидов) может сопровождаться извращением вкуса, сухостью во рту, кровоточивостью десен, глосситом, катаральным и язвенным стоматитом, кандидозом полости рта. При длительном приеме пациентами глюкокортикостероидных гормонов (ГКС) стоматологу следует учитывать их иммунодепрессивное действие, проявляющееся замедлением процессов регенерации, снижением устойчивости к инфекциям. Применение других препаратов с иммунодепрессивным действием (метотрексат, азатиоприн и др.) дополнительно может сопровождаться развитием язвенного стоматита, гингивита, повышенной кровоточивости (вследствие развития тромбоцитопении).

\section{Воспалительные изменения слизистой оболочки полости рта могут служить первыми клиническими проявлениями болезни Крона или же наблюдаться одновременно с поражением подвздошной и толстой кишок. Чаще всего обнаруживаются афтозный стоматит, макрохейлия (увеличение губ) или изменения рельефа слизистой оболочки в виде «булыжной мостовой»}

У пациентов с хроническими воспалительными заболеваниями кишечника также следует помнить о возможных побочных эффектах лекарственных препаратов, применяемых для лечения этих заболеваний. Для инфликсимаба, аминосалицилатов, ГКС и иммуносупрессоров характерны повышенная кровоточивость (вследствие тромбоцитопении) и угнетение иммунитета, проявляющееся замедлением заживления ран, снижением устойчивости к инфекциям. Использование инфликсимаба может быть причиной хейлита, отека лица и губ аллергического генеза, герпетических высыпаний, лимфоаденопатии, васкулита (преимущественно кожного), кандидоза полости рта. При приеме аминосалицилатов отмечается сухость во рту и стоматит. Терапия иммуносупрессорами (метотрексат, азатиоприн и др.) может сопровождаться развитием язвенного стоматита и гингивита [27].

\section{Прием челого ряда препаратов для лечения} заболеваний желчного пузыря и желчевыводящих путей также может сопровождаться побочными эффектами со стороны органов и тканей полости рта - сухостью во рту (метацин, платифиллин, атропин, пирензепин, гиосцина бутилбромид, бенциклана фумарат), изменением вкусовых ощущений

Безусловно, при наличии у гастроэнтерологического пациента стоматологических проблем оптимальным является участие стоматолога в его курации. Однако традиционно основными поводами обращения к стоматологу являются острая зубная боль и появление кариеса. Обращения по поводу изменений слизистой оболочки полости рта и профилактические визиты в структуре причин посещения стоматолога в большинстве опросов составляют лишь около 10\%. Кроме этого, отмечается и отчетливая тенденция «откладывания на потом» визита к стоматологу, объясняемая боязнью, отсутствием времени, материальными затруднения и другими причинами [28-30].

В этой связи при курации гастроэнтерологических пациентов с наличием стоматологических проблем интернисту целесообразно дать пациенту и определенные лечебно-профилактические рекомендации, что особенно актуально с учетом возможных побочных эффектов лекарственной терапии. Необходимо рекомендовать современные натуральные средства по уходу за полостью рта (зубная паста, ополаскиватель, спрей), произведенные по стандартам GMP, в состав которых входят масла и экстракты шалфея и мяты, гвоздичное масло, фенилсалицилат, тимол, эвгенол, натрия фторид, оказывающие воздействие на различные симптомы, обладая противовоспалительным, антибактериальным, антикариозным и дезодорирующим эффектами.

Применение в стоматологической практике натуральных растительных препаратов помогает снять воспаление, раздражение, боль, жжение, отек, уменьшить кровоточивость десен и неприятный запах изо рта. Их состав подобран таким образом, чтобы обеспечивать воздействие на разные группы микроорганизмов ротовой полости независимо от этиологического фактора. Например, тимол и эфирные масла оказывают антисептическое (антибактериальное и противогрибковое действие) на слизистую оболочку ротовой полости и десен. Тесты in vitro доказали, что эфирные масла шалфея обладают бактерицидным действием в отношении грампозитивных и грамнегативных бактерий, а также фунгицидным действием против Candida albicans. Также необходимо отметить, что в состав некоторых средств входит натрия фторид, стимулирующий минерализацию твердых тканей зуба, способствуя созреванию и увеличению твердости зубной эмали, предохраняя зубы от развития кариеса. 
Эффективность и безопасность применения растительных препаратов продемонстрирована в ряде клинических исследований в лечении воспалительных заболеваний пародонта (гингивит, пародонтит) и воспалительных заболеваний слизистой оболочки полости рта [31-33]. Их применение позволяет стабилизировать воспалительный процесс, уменьшить степень функциональных и структурных нарушений пародонта, нормализовать состав микрофлоры полости рта, обеспечить стабильную положительную динамику пародонтальных индексов и в итоге повысить эффективность лечения.

При воспалительных заболеваниях полости рта (стоматит, гингивит, пародонтоз) рекомендовано использо- вать комплекс средств: зубную пасту - чистить зубы не менее 2 раз в день утром и вечером 2-3 минуты, затем использовать раствор для местного применения - ежедневно утром и вечером после чистки зубов или спрей наносить в виде орошений на полость рта. В течение дня, после приема пищи, между чисткой зубов рекомендовано применять ополаскиватель.

Знание гастроэнтерологами и стоматологами изменений со стороны органов и тканей полости рта при заболеваниях пищеварительной системы, а также возможного влияния лекарственной терапии этих заболеваний на состояние полости рта, их профилактика и лечение позволят улучшить качество оказания медицинской помощи и улучшить качество жизни пациентов.

\section{ЛИТЕРАТУРА}

1. Трухан Д.И., Викторова И.А.,Трухан Л.Ю. Изменение органов и тканей полости рта при заболеваниях внутренних органов. М.: Практическая медицина, 2012. 208 с.

2. Трухан Л.Ю., Трухан Д.И., Викторова И.А Изменение органов и тканей полости рта при заболеваниях внутренних органов. Справочник поликлинического врача, 2011, 7: 8-14.

3. Трухан Д.И., Викторова И.А. Внутренние болезни: Гастроэнтерология. СПб.: СпецЛит, 2013. 367 с

4. Трухан Д.И., Голошубина В.В., Трухан Л.Ю. Изменения со стороны органов и тканей полости рта при гастроэнтерологических заболеваниях. Экспериментальная и клиниче ская гастроэнтерология, 2015, 3: 88-91.

5. Трухан Л.Ю, Тарасова Л.В., Трухан Д.И. Изменения со стороны органов и тканей полости рта при болезнях органов пищеварения. Dental Tribune, 2013, 5: 7.

6. Трухан Д.И., Трухан Л.Ю., Викторова И.А. Изменение органов и тканей полости рта при болезнях органов пищеварения. Материалы XX международной научно-практической конференции «Актуальные вопросы стоматологии» (Омск, 4-6 марта 2014 г.). Омск: Изд-во ОмГМА, 2014. С. 197-9.

7. Трухан Л.Ю., Трухан Д.И. Стоматологические проблемы гастроэнтерологических пациентов. Dental Tribune Russia, 2015, 2: 12.

8. Лазебник Л.Б., Машарова А.А., Бордин Д.С. и др. Многоцентровое исследование «Эпидемиология гастроэзофагеальной рефлюксной болезни в России» (МЕГРЕ): первые итоги. Экспериментальная и клиническая гастроэнтерология, 2009, 6: 4-12.

9. Трухан Д.И., Тарасова Л.В., Филимонов С.Н., Викторова И.А. Болезни пищевода, желудка и двенадцатиперстной кишки. Клиника, диагностика и лечение. СПб.: СпецЛит. 2014. 160 с.

10. Трухан Д.И. Гастроэзофагеальная рефлюксная болезнь и функциональная диспепсия: выбор прокинетика с позиций клинической эффективности и лекарственной безопасности Российский журнал гастроэнтерологии, гепатологии, колопроктологии, 2014, 5: 77-85.
11. Bickley J, Owen RJ, Frazer AG. Evaluation of the polymerase chain reaction for detecting the uve $C$ gene of Helicobacter pylori in gastric biopsy samplex and dental plaque. J. Clinic. Microbiol, 1993, 39: 338-44.

12. Nguyen AH, Engstrand L, Genta RH. Detection of Helicobacter pylori in dental plaque by reverse transcription polymerase chain reaction. J. Clinic. Microbiol., 1993, 31: 783-7.

13. Santamaria MJ, Varea C V, Munoz Almagro MC. Dental plaque in Helicobacter pylori infection. An Esp Pediatr, 1999, 50: 244-6.

14. Dye BA, Kruszon-Moran D, McQuillan G. The relationship between periodontal disease attributes and Helicobacter pylori infection among adults in the United States. Am J Public Health, 2002, 92: 1809-15.

15. Арутюнов С.Д. Заболевания пародонта и «системные болезни»: известное прошлое, многообещающее будущее. Пародонтология, 2009, 1: 3-6.

16. Butt AK, Khan AA, Khan AA et al. Correlation of Helicobacter pylori in dental plaque and gastric mucosa of dyspeptic patients. J Pak Med Assoc, 2002, 52: 196-200.

17. Cellini L, Allocati N, Piattelli A et al. Microbiological evidence of Helicobacter pylor from dental plaque in dyspeptic patients. New Microbiol, 1995, 18: 187-92.

18. Savoldi E, Marinone MG, Negrini R et al. Absence of Helicobacter pylori in dental plaque determined by immunoperoxidase. Helicobacter, 1998, 3: 283-7.

19. Mattana CM, Vega AE, Flores $G$ et al. Isolation of Helicobacter pylori from dental plaque. Rev Argent Microbiol, 1998, 30: 93-5.

20. Трухан Д.И., Тарасова Л.В., Трухан Л.Ю. Изменения органов и тканей полости рта при заболеваниях сердечно-сосудистой системы и соединительной ткани, и их лекарственной терапии. Consilium Medicum, 2014, 1: 79-82.

21. Трухан Л.Ю., Трухан Д.И. Изменения со стороны органов и тканей полости рта при диффузных заболеваниях соединительной ткани. Dental Tribune, 2014, 2: 25.

22. Трухан Д.И. Аутоиммунный вариант течения хронического панкреатита. Российский гастроэнтерологический журнал, 1999, 2: 54-61.
23. Трухан Д.И. Клинико-иммунологические варианты течения хронического панкреатита. терапевтический архив, 2001, 2: 20-4.

24. Лазебник Л.Б., Лычкова А.Э., Михайлова З.Ф. Полиморбидность при воспалительных заболеваниях кишечника. Бюллетень экспериментальной биологии и медицины, 2012, 1: 35-8.

25. Тарасова Л.В., Трухан Д.И. Болезни кишечника. Клиника, диагностика и лечение: учебное пособие. СПб.: СпецЛит, 2013. 144 с.

26. Тарасова Л.В., Трухан Д.И. Лекарственная безопасность в гастроэнтерологии.

Экспериментальная и клиническая гастроэнтерология, 2013, 4: 81-7.

27. Трухан Д.И., Филимонов С.Н. Дифференциальный диагноз основных гастроэнтерологических синдромов и симптомов. Новокузнецк: ООО «Полиграфист». 2015. 124 с.

28. Гринин В.М., Караханян В.Т., Максимовский Ю.М. Анализ причин обращаемости пациентов в платные стоматологические учреждения и оценка ими качества работы врачей. Стоматология для всех, 2003, 2. URL: http:// www.e-stomatology.ru/pressa/ periodika/ st_d_f/2_2003/\#1

29. Родина Т.С., Коновалов О.Е. Причины обращения за стоматологической помощью взрослого населения крупного города в медицинские организации различных форм собственности. Российский медико-биологический вестник им. академика И.П. Павлова, 2010, 2: 68-72.

30. Воробьев М.В. Причины обращения за медицинской помощью стоматологических пациентов с наркотической зависимостью. Фундаментальные исследования, 2013, 7(1): 36-41.

31. Рабинович И.М., Григорьянц Л.А., Герчиков Л.Н., Гурин А.Н., Островский А.Д. Опыт клинического применения препарата «Пародонтоцид» при патологии слизистой оболочки рта. Медицинский бизнес, 2008, 1(163): 42-3.

32. Макеева И.М., Туркина А.Ю., Полякова М.А., Бабина К.С. Применение раствора Пародонтоцид в комплексном лечении и профилактике гингивита. Стоматология, 2013, 6: 29-32.

33. Туркина А.Ю. Использование препаратов серии «Пародонтоцид» в комплексном лечении воспалительных заболеваний пародонта. Фарматека, 2014, 3: 14. 